\title{
As vozes dos estudantes universitários com deficiência nas instituições públicas de ensino superior no Brasil e em Portugal (2008 - 2015)
}

\author{
Francisco-Ricardo Lins-Vieira de Melo, Maria-Helena Martins, Maria-Leonor Borges y Teresa
}

\section{Gonçalves}

\section{RESUMO}

O presente estudo tem como objetivo analisar a produção científica do Brasil e de Portugal sobre a inclusão de estudantes com deficiência no ensino superior. A metodologia adotada consistiu na análise de dissertações de mestrado e teses de doutoramento que abordam as vozes e as experiências dos estudantes com deficiência. As vozes dos estudantes revelam que, embora sejam referidas em ambos os países práticas cada vez mais inclusivas, estas ações ainda são insuficientes para garantir a sua permanência e participação na vida universitária. Estes indicadores podem contribuir para guiar a elaboração de políticas e práticas que respondam aos desafios da inclusão no ensino superior.

Palavras chave: ensino superior; inclusão educacional; estudantes com deficiência; vozes dos estudantes.

Francisco-Ricardo Lins-Vieira de Melo

ricardolins67@gmail.com Brasileiro. Doutor em Educação pela Universidade Federal do Rio Grande do Norte (UFRN), Brasil; Graduado em Fisioterapia pela Universidade Federal da Paraíba, Brasil. Professor Assitente do Departamento de Fisioterapia do Centro de Ciências da Saúde e do Programa de Pós-Graduação em Educação e Presidente da Comissão Permanente de Apoio ao Estudante com Necessidade Educacional Especial (CAENE) da UFRn. Áreas de investigação: educação inclusiva, ensino superior, pessoas com deficiência e políticas de inclusão.

\section{Maria-Helena Martins}

mhmartin@ualg.pt Portuguesa. Doutora em Psicologia Educacional pela Universidade do Algarve, Portugal, Mestre em Educação Especial pela Universidade Técnica de Lisboa. Professora Auxiliar da Faculdade de Ciências Humanas e Sociais Universidade do Algarve, Portugal, coordenadora do Gabinete de Apoio ao Estudante com Necessidades Educativas Especiais, Universidade do Algarve, Portugal. Áreas de investigação: a inclusão, pessoas com deficiência, políticas de inclusão e ensino superior, intervenção precoce, resiliência e envelhecimento.

\section{Maria-Leonor Borges}

Portuguesa. Doutora em Educação com especialidade em Formação de Professores pelo Instituto da Educação da Universidade de Lisboa, Portugal, Mestre em Análise Social da Educação pela Universidade de Lisboa, Portugal. Professora Adjunta da Escola Superior de Educação e Comunicação da Universidade do Algarve e Diretora do Mestrado em Educação Especial e membro do Gabinete de Apoio ao Estudante com Necessidades Educativas Especiais da Universidade do Algarve, Portugal. Áreas de investigação: formação de professores (conhecimento e desenvolvimento profissional), políticas educativas e inclusão educativa e estudos na área da deficiência. investigação: Educação e Formação de adultos, estudantes não-tradicionais com necessidades educativas especiais. 
Las voces de los estudiantes universitarios con discapacidad en las instituciones públicas de educación superior en Brasil y en Portugal (2008-2015)

\section{RESUMEN}

El presente estudio tiene como objetivo analizar la producción científica de Brasil y de Portugal respecto a la inclusión de estudiantes con discapacidad en la educación superior. La metodología adoptada consistió en el análisis de investigaciones de maestría y tesis de doctorado que abordan las voces y las experiencias de los estudiantes con discapacidad. Dichas voces revelan que, aunque ambos países refieran prácticas cada vez más inclusivas, estas acciones aún son insuficientes para garantizar la permanencia y participación de los estudiantes en la vida universitaria. Los indicadores utilizados pueden ayudar a guiar la elaboración de políticas y prácticas que respondan a los desafíos de la inclusión en la educación superior.

Palabras clave: educación superior, inclusión educativa, estudiantes con discapacidad, voces de estudiantes.

\section{The Voices of University Students with Disabilities in Public Higher Education Institutions in Brazil and Portugal (2008-2015)}

\section{ABSTRACT}

This study aims to analyze the scientific production of Brazil and Portugal on the inclusion of students with disabilities in higher education. The methodology adopted consisted of the analysis of master's dissertations and doctoral theses that address the voices and experiences of disabled students. The students' voices reveal that, although increasingly inclusive practices are mentioned in both countries, these actions are still insufficient to guarantee their permanence and participation in university life. These indicators can help to guide the development of policies and practices that respond to the challenges of inclusion in higher education.

Key words: higher education, educational inclusion, students with disabilities, students' voices. 


\section{Introdução}

Reflexo da promoção nas sociedades modernas democráticas de políticas de combate à exclusão social de minorias (gênero, etnia, cultura, religião), em que se enquadra a população com deficiência, a inclusão é sinónimo de luta contra todas as formas de desigualdade social.; enquanto movimento social e político defende o direito de todos os indivíduos participarem, de uma forma consciente e responsável na sociedade e de serem aceites e respeitados independentemente daquilo que os diferencia.

Nas palavras de Barton (2009), a inclusão não é um "fim”, mas um "processo" que pretende alcançar o objetivo de caminhar para a equidade de todos, reconhecendo e apoiando a riqueza da diversidade social e contrariando, no caso dos indivíduos com deficiência, os redutores parâmetros culturais de normalidade. No cerne do movimento inclusivo estão os valores do respeito pela diferença, da igualdade de oportunidades e da equidade para a construção, e consolidação de sociedades inclusivas (Runswick-Cole, 2011).

Como movimento educacional, a inclusão centra-se na necessidade de as instituições educacionais mudarem as suas culturas e práticas de forma a garantir uma educação adequada a todas as pessoas da sociedade, aumentando a sua participação e procurando diminuir e eliminar todo o tipo de processos que levam à exclusão social (Barton, 2009). Assim, a escola inclusiva deve procurar responder com alta qualidade à diferença tendo em vista o desenvolvimento das capacidades e competências de todos os estudantes (Martins, 2000).

O ingresso de estudantes com deficiência ao ensino superior começa a ser uma realidade em muitas universidades de diversos países em resposta às diretrizes internacionais e à luz do paradigma da educação inclusiva (Alarcón et al., 2013; Castro, 2011; Hadjikakou e Hartas, 2008; Rodriguez-Martin e Alvarez-Arregui, 2014). Contudo, este paradigma encontra-se ainda embrionário em muitos países e, em função da complexidade que assume esse processo e das peculiaridades socioculturais, políticas e econômicas, podem constatar-se diferentes estágios de implementação e evolução (Booth e Ainscow, 2002; Kyriazopoulou e Weber, 2009), inclusive no Brasil e em Portugal. Assinale-se que, enquanto no Brasil as políticas se encontram alicerçadas por uma expressiva legislação, em Portugal constata-se a ausência de uma legislação específica para o ensino superior, cabendo às instituições, singularmente, a iniciativa de fomentar e regulamentar práticas que respondam às necessidades dos estudantes (Melo e Martins, 2016; Santos, 2013).

Efetivamente, no Brasil, as discussões em torno da inclusão no ensino superior iniciam na década do anos 90 e tomam maior relevo em 2005 com a criação do Programa Incluir do Ministério da Educação propondo ações para o acesso e permanência das pessoas com deficiência nas instituições federais de ensino superior. Mas, é a partir de 2008, com a publicação da política educacional inclusiva, que esse processo se materializa com o Decreto 6.571(2008) revogado pelo Decreto 7.611 (2011) assegurando apoio técnico e financeiro ao sistema público de ensino a ser prestado pelo governo federal, destacando entre outras ações a estruturação dos núcleos de acessibilidade com vistas a dar o suporte educacional que demandam as necessidades dos estudantes com deficiência, com altas habilidades/superdotação e com transtornos globais do desenvolvimento (Melo e Martins, 2016).

Os reflexos da política educacional no contexto brasileiro evidenciam o crescimento de matrículas de estudantes com deficiência no ensino superior. De 2003 a 2013 houve um aumento de 575,4\% no número de matrículas, passando de 5.078 para 29.221 matrículas, respectivamente (Ministério da Educação, 2013).

Esta nova realidade, embora sinalize avanços no que tange ao ingresso, ainda apresenta um grande distanciamento entre o que está preconizado no discurso legal e a garantia das condições para uma 
efetiva participação e sucesso acadêmico e social dessa população no ensino superior (Cabral e Melo, 2017).

Em Portugal e, embora na lei que define as bases gerais do Regime Jurídico da Prevenção, Habilitação, Reabilitação e Participação da Pessoa com Deficiência (Lei 38/2004) o Estado Português assuma o seu empenho na concretização de uma política global, integrada e transversal de prevenção, habilitação, reabilitação e participação da pessoa com deficiência, verifica-se que no ensino superior escasseia a legislação (Melo e Martins, 2016). De fato, se bem que seja competência do Estado adotar medidas específicas necessárias para assegurar o acesso da pessoa com deficiência à educação e ao ensino inclusivo, a referência a alunos com deficiência e incapacidade no ensino superior encontra-se na Portaria 787/85, de 17 de outubro de 1985, onde se estabelece a afixação anual do numerus clausus especificamente para candidatos portadores de habilitação legal que sejam deficientes físicos ou sensoriais (Martins, Borges, Fonseca, Gonçalves e Ferreira, 2015).

Neste sentido, e tendo como referencial as orientações e políticas nacionais e internacionais no âmbito da educação inclusiva, as instituições do ensino superior têm vindo a implementar medidas de apoio e suporte aos direitos dos estudantes com deficiência, criando serviços ou gabinetes de apoio que respondam às necessidades deste público que cada vez mais procuram este nível de ensino. Importa, contudo assinalar que a presença destes estudantes continua minoritária, marcada muitas vezes por abandono precoce e insucesso acadêmico, apontando-se como causas fundamentais as barreiras arquitetônicas, a falta de adequação dos processos de ensino-aprendizagem, a desadequação do processo e/ou instrumentos de avaliação, a ausência de recursos educativos adequados e, principalmente, as barreiras atitudinais (Martins, Borges, e Gonçalves, 2017).

Apesar destas diferenças, nas últimas décadas, tem-se assistido em ambos os países a avanços significativos no acesso e permanência das pessoas com deficiência neste nível de ensino (Melo e Martins, 2016).

\section{Protagonismo das pessoas com deficiência na produção do conhecimento científico}

No contexto de produção de conhecimento sobre a temática educação inclusiva no ensino superior, diversos estudos têm vindo a privilegiar como sujeitos os estudantes com deficiência ou com outras necessidades educativas especiais (NEE). Esta opção enquadra-se num modelo epistemológico que procura romper com "o fenômeno de invisibilidade estrutural das pessoas com deficiência" (Martins, Fontes, Hespanha e Berg, 2012: 46) e no reconhecimento de que a opção como "perspectivamos a deficiência é essencial na forma como definimos os problemas e delineamos as soluções" (Martins et al., 2012: 48).

Assinale-se que esta abordagem se tem vindo a afirmar no estudo de temas relacionados com pessoas ou grupos que historicamente foram alvo de exclusão social, como o das pessoas com deficiência, em que se reconhece e valoriza as suas vozes e experiências e a legitimidade de participar das discussões e tomadas de decisões que dizem respeito à sua vida (ONU, 2006; Relatório Mundial sobre Deficiência, 2012).

Em termos históricos esta perspectiva investigativa de rompimento do silêncio das vozes e participação das pessoas com deficiência surgiu, nos Estados Unidos da América e no Reino Unido, na década de 70, com os movimentos sociais de pessoas com deficiência e com a consequente politização da questão da deficiência (Barnes, 2003; Barton, 2009; Oliver, 1997). Neste âmbito, emergem os estudos da deficiência (Disability Studies), posteriormente denominados de "Investigação Emancipatória da Deficiência" (Oliver, 1992), assentes no "compromisso político com a denúncia da opressão social das pessoas e na aspiração de uma sociedade mais inclusiva" (Martins et al., 2012: 46). Aspirando ao empowerment das pessoas com deficiência (Barnes, 2003; Fontes, 2009), estes estudos pretendem produzir conhecimento sobre as 
estruturas econômicas, políticas, culturais e ambientais que criam e legitimam as múltiplas privações com que se defrontam às pessoas com deficiência e suas famílias. O reconhecimento da importância do envolvimento na primeira pessoa da pessoa com deficiência no processo de investigação é apontado como fundamental para a sua capacitação. (Barnes, 2003; Barton, 2009; Oliver, 1997; Oliver e Barnes, 2012).

As questões da educação inclusiva e do acesso à universidade das pessoas com deficiência constituem atualmente uma temática extremamente relevante, quer no âmbito nacional quer internacional (Harrison et al., 2009; UNESCO, 1994). As investigações nesta área têm ganho visibilidade sendo que diversos investigadores alertam para que a permanência de estudantes com deficiência no ensino superior pode resultar em fracasso devido às diversas barreiras que continuam a existir nas universidades, denunciando um ambiente potencializador da manutenção da exclusão neste nível de ensino (Abreu, 2013; Alarcón et al., 2013; Diez e Romo, 2011; Silva, 2014). É neste sentido que importa apoiar estes estudantes que apresentam alguma diversidade funcional para fortalecer o seu processo de ensino-aprendizagem e o seu sucesso acadêmico (Márquez-Ramírez, 2015).

Estudiosos como Booth e Ainscow (2002) e Kyriazopoulou e Weber (2009) prevendo a complexidade que envolve a implementação do paradigma da educação inclusiva, a partir das singularidades e contextos de cada país, têm sinalizado indicadores chaves, tais como as políticas, a legislação, a formação de professores, as infraestruturas, os serviços de apoio, o financiamento e a intersetorialização. São ainda identificadas como condições necessárias para garantir o êxito da trajetória acadêmica destes estudantes: a existência de tecnologias assistidas e outros recursos educativos adequados; a oferta de apoio especializado; a adequação dos métodos de ensino e aprendizagem; a formação de professores; ausência de barreiras arquitetônicas; a oferta de acomodações adequadas; a existência de legislação e ainda, a criação de apoios sociais que permitam fazer face a dificuldades financeiras e sociais (Luque-Parra et al., 2014; Pereira et al., 2016).

Pretendendo-se analisar o protagonismo dos universitários com deficiência no contexto da produção científica stricto sensu, o presente artigo tem como objetivo revelar o que as teses e dissertações apresentam sobre as experiências destes universitários no contexto das instituições públicas de ensino superior do Brasil e de Portugal. O foco nestes países não tem o propósito de comparar, mas de conhecer a realidade de ambos, considerando os distintos contextos de políticas de inclusão (Melo e Martins, 2016).

A relevância do presente estudo parte da hipótese que as vozes destes estudantes com deficiência podem suscitar importantes reflexões e direcionamentos, contribuindo para a melhoria da qualidade da resposta aos desafios da inclusão no Ensino Superior.

\section{Percurso metodológico}

O presente estudo consiste numa revisão sistemática tendo como referencial a investigação de literatura científica já tornada pública. Tem como principal finalidade "colocar o pesquisador em contato direto com tudo o que já foi estudado, dito ou filmado sobre determinado assunto" (Marconi e Lakatos, 2008: 56).

Neste sentido, o estudo justifica-se pelo atual contexto mundial da política de educação inclusiva, especificamente no ensino superior, visando refletir acerca dos achados das pesquisas sobre as experiências de estudantes com deficiência nas universidades públicas brasileiras e portuguesas. Este interesse decorre ainda de que estes países se encontram em situações distintas, em termos de normatização jurídica para assegurar o acesso e a permanência desse alunado neste nível de ensino (Melo e Martins, 2016). Espera-se que possa contribuir para um maior entendimento e compreensão de como está a desenvolver-se este processo, os seus aspectos importantes e as suas fragilidades. 
O mapeamento das produções acadêmicas foi solicitado diretamente à Fundação Coordenação de Aperfeiçoamento de Pessoal de Nível Superior (CAPES) no Brasil. No que se refere a Portugal, considerando a reestruturação que está a ser feita aos serviços a nível nacional ${ }^{1}$, foi necessário fazer uma triangulação desse levantamento por meio do Repositório Científico de Acesso Aberto de Portugal (RCAAP), dos Repositórios Científicos das Universidades públicas portuguesas e do Registro Nacional de Teses e Dissertações (RENATES).

Para realizar a pesquisa foram adotados os seguintes critérios de inclusão: a) dissertações e teses publicadas num intervalo temporal de 2008 a 2015 sobre experiências, testemunhos ou percepção dos estudantes com deficiência no ensino superior, b) o contexto da pesquisa deveria ser realizado em universidades públicas. Os critérios de exclusão foram: dissertações ou teses com registro repetidos, indisponíveis e que não tratam das experiências dos estudantes com deficiência no ensino superior.

A opção por este recorte temporal coincide com a política de educação especial na perspectiva inclusiva vigente no Brasil e do Decreto 3/2008, última normativa legal publicada em Portugal direcionada para a educação das pessoas com deficiência (Grupo de Trabalho da Política Nacional de Educação Especial, 2008; Decreto 3/2008).

Finalizada essa etapa, foram enquadradas 31 produções acadêmicas $(\mathcal{N}=31)$ para constituir o corpus de análise, sendo 26 brasileiras e 5 portuguesas. Todos os trabalhos selecionados foram lidos, analisados e catalogados. Os dados relevantes para o estudo foram obtidos a partir de um roteiro inserido no software Excel (2010), contendo os seguintes campos: título, autor, nível (mestrado ou doutorado), ano de defesa, instituição de ensino superior (IES) em que foi defendida a investigação, região, programa de pós-graduação, caracterização metodológica da pesquisa (abordagem/tipo de pesquisa), caracterização dos participantes (tipo de deficiência, nível de ensino, gênero, idade curso/área de conhecimento), local onde foi desenvolvida a pesquisa, referencial teórico (pedagógico, psicológico, sociológico), instrumentos de pesquisa e tipo de análise da pesquisa.

A partir das informações registradas foram construídos dois eixos para análise e discussão dos resultados: o primeiro focado na caracterização (por meio de análise quantitativa em estatística descritiva básica) e o segundo nas revelações das produções acadêmicas (por meio da análise qualitativa utilizando categorias temáticas segundo Bardin, 1999). A organização da análise procedeu-se em três fases: 1) a pré-análise, que corresponde à escolha de documentos a serem submetidos a análise, a formulação de hipóteses e objetivos e a elaboração dos indicadores que fundamentem a interpretação final; 2) a exploração do material, que consiste na aplicação sistemática das decisões tomadas na fase anterior, abrangendo, fundamentalmente a codificação, a decomposição ou enumeração; e 3) o tratamento dos resultados obtidos que corresponde ao tratamento dos dados de forma a serem significativos e válidos (Bardin, 1999).

\footnotetext{
${ }^{1}$ Atualmente o registo da informação a nível nacional referente a dissertações e teses está passando por uma reestruturação, no sentido de melhorar o acesso a essa informação. Este processo iniciou-se em 2013 com o Decreto-Lei 115/2013, que determina que as dissertações de mestrado e teses de doutoramentos devem ser registados nos repositórios institucionais de cada instituição de Ensino Superior, que integram a rede RCAAP - Repositório Científico de Acesso Aberto em Portugal. Visando acelerar o processo é publicado a Portaria 285/2015, estabelecendo-se nas suas disposições transitórias as datas de 31 de julho e de 31 de dezembro como prazos limite para o depósito de todas as dissertações de mestrado e teses de doutoramento, concluídas respetivamente, entre a entrada em vigor do Decreto-Lei 115/2013 e a referida portaria. No entanto, no que se refere ao registo e disponibilização de informação referente aos trabalhos produzidos nos anos anteriores a 2013, as universidades portuguesas têm feito um esforço para concluir este processo o que se tem revelado demorado, uma vez que requer a autorização dos autores e a digitalização dos trabalhos.
} 


\section{Resultados e discussão}

\section{Caracterização das produções acadêmicas}

Das 31 produções acadêmicas $(\mathcal{N}=31)$ que constituem o presente corpus de análise identificadas (Teses da CAPES, no RCAAP, nos Repositórios Científicos das Universidades públicas portuguesas e no RENATES) no período compreendido entre 2008 e 2015, encontramos 23 dissertações de mestrado (uma decorrente de mestrado profissionalizante) e 8 teses de doutoramento. Relativamente às produções do Brasil foram produzidas 19 dissertações de mestrado e 7 de doutoramento, sendo que em Portugal se encontraram 4 dissertações de mestrado e 1 de doutoramento (tabela 1).

Os resultados revelam que nos dois países a temática pesquisada nos últimos sete anos tem sido explorada mais nas dissertações de mestrado (Brasil, $\mathrm{n}=19$; Portugal, $\mathrm{n}=4$ ), do que nas teses de doutoramento (Brasil, $\mathrm{n}=7$; Portugal, $\mathrm{n}=1$ ), constatando-se alguma variabilidade no número de produções por ano. Assinale-se que a partir de 2013 até 2015 o número de trabalhos aumentou e estabilizou em seis produções acadêmicas em que se dá enfoque à voz dos estudantes com deficiência $(n=19 \%)$.

Constata-se ainda que no Brasil a produção científica encontrada surge em 2009 (uma tese de doutoramento) e vai progredindo com dissertações de mestrado e de doutoramento com alguma regularidade até ao final do período investigado. Com uma menor expressão, atendendo à proporcionalidade do número de instituições de ensino superior, verifica-se que, em Portugal, a produção científica se inicia em 2013, com dissertações de mestrado. De salientar que apenas foi encontrada uma tese de doutoramento em Portugal (2014).

Apesar da temática inclusão estar em evidência em muitas discussões mundiais e expressa em diversos normativos internacionais e nacionais nos dois países em análise, os dados recolhidos permitem apurar que a investigação sobre a inclusão de estudantes com deficiência no ensino superior, focalizando os próprios estudantes ainda pode ser considerada uma temática recente e até embrionária, sobretudo em Portugal. Esta constatação é particularmente

Tabela 1. Distribuição anual e por nível das dissertações e teses

(Brasil e Portugal)

\begin{tabular}{|c|c|c|c|c|c|c|}
\hline \multirow{2}{*}{ Ano } & \multicolumn{2}{|c|}{ Mestrado } & \multicolumn{2}{c|}{ Doutorado } & \multirow{2}{*}{ N } & \% \\
\cline { 2 - 6 } & Brasil & Portugal & Brasil & Portugal & \\
\hline 2009 & 0 & 0 & 3 & 0 & 3 & 9.5 \\
\hline 2010 & $2^{*}$ & 0 & 0 & 0 & 2 & 5 \\
\hline 2011 & 4 & 0 & 2 & 0 & 6 & 9 \\
\hline 2012 & 3 & 0 & 0 & 0 & 3 & 9.5 \\
\hline 2013 & 3 & 2 & 1 & 0 & 6 & 19 \\
\hline 2014 & 2 & 2 & 1 & 1 & 6 & 19 \\
\hline 2015 & 5 & 0 & 0 & 0 & 6 & 19 \\
\hline Total & $\mathbf{1 9}$ & $\mathbf{4}$ & $\mathbf{7}$ & $\mathbf{1}$ & $\mathbf{3 1}$ & $\mathbf{1 0 0}$ \\
\hline
\end{tabular}

Fonte: Banco de Teses da CAPES, RCAAP, Repositórios Cientificos das Universidades públicas portuguesas e RENATES.

*Um dos mestrados é decorrente de Mestrado Profissionalizante. 
relevante, tendo em atenção que o ingresso destes estudantes com deficiência no ensino superior tem vindo a aumentar progressivamente. Este resultado reflete e corrobora os dados da investigação na área que assume que o paradigma da educação inclusiva depende das peculiaridades socioculturais, políticas e econômicas, resultando em diferentes estágios de implementação e evolução (Booth e Ainscow, 2002; Kyriazopoulou e Weber, 2009; Melo e Martins, 2016; Santos, 2013).

Da análise em curso parece evidenciar-se ainda que, considerando a desproporcionalidade da produção acadêmica entre os dois países (Brasil e Portugal), o desenvolvimento da política inclusiva no Brasil, tem vindo a favorecer mais significativamente as investigações na área, com o objetivo de uma melhor compreensão dessa realidade em processo, em detrimento da realidade portuguesa. Tal como se referiu anteriormente, em Portugal constata-se a ausência de uma legislação específica para o ensino superior, sendo que cada instituição tem vindo a regulamentar práticas que pretendem responder às necessidades dos seus estudantes (Melo e Martins, 2016; Santos, 2013).

Outro aspecto assaz importante e que convém refletir é que a produção acadêmica relacionada a estudos que analisam as experiências e testemunhos destes estudantes no Ensino Superior, de certo modo ainda é bastante tímida e pouco expressiva em ambos países, tendo como referencial o período em estudo (sete anos). Assinale-se que esta carência de protagonismo dos próprios estudantes com deficiência e da fraca atenção que os investigadores lhes conferem é corroborada pela literatura científica que refere a "invisibilidade estrutural das pessoas com deficiência" (Martins et al., 2012: 46). Não obstante tal, é possível concluir que a participação e as vozes das pessoas com deficiência estão começando a serem protagonizadas nas investigações, dado este que é defendido por alguns investigadores, que reclamam a imprescindibilidade de se ouvir os próprios estudantes, de modo a valorizar a importância do que estes têm a dizer para as mudanças que se relacionam com as suas próprias vidas (Diez e Romo, 2011).

Na realidade brasileira as 26 produções acadêmicas foram defendidas em 16 instituições de ensino superior, das quais 11 possuem vinculação administrativa federal e cinco estadual. Estão localizadas nas regiões: sudeste (6), nordeste (6), sul (2), norte (1) e centro-oeste (1) do Brasil (tabela 2).

No que se refere às produções portuguesas conclui-se que uma das produções foi apresentada na Universidade da Madeira (Ilhas), sendo que as restantes foram defendidas em Portugal continental, nomeadamente duas na Universidade de Aveiro (norte litoral), e na Universidade de Trás os Montes e Alto Douro (norte interior) e Universidade do Algarve (sul), respetivamente com uma produção cada (tabela 3).

Constatou-se, no Brasil, que a predominância dos trabalhos está vinculada a Programas de Pós-graduação da área de Educação $(n=20)$, entre os quais apenas dois de Educação Especial. Os restantes programas são: Planejamento e Políticas Públicas, Gestão Social, Educação e Desenvolvimento Local, Controladoria e Contabilidade, Psicologia e Psicologia da Educação, respectivamente com uma produção cada um (tabela 4).

Tal como no Brasil, também em Portugal se verifica uma predominância dos trabalhos vinculados a programas de pós-graduação da área de Educação, mais especificamente nas Giências da Educação $(\mathrm{n}=3)$, seguindo-se um em Psicologia e um outro em Educação Especial (tabela 5).

Ao se analisar o gênero em relação às produções identificadas apura-se, quer no Brasil (tabela 4), quer em Portugal (tabela 5), uma predominância feminina tanto em relação à autoria (Brasil: $\mathrm{n}=22$; Portugal: $\mathrm{n}=5$ ), quer relativamente à orientação (Brasil: $\mathrm{n}=17$; Portugal: $\mathrm{n}=4)$. Estes resultados corroboram com outros estudos sobre a participação feminina na Ciência, particularmente na Educação (Rigolin et al., 2013; Gonçalves e Hayashi, 2014). 
Tabela 2. Distribuição dos trabalhos por instituição - Brasil

\begin{tabular}{|c|c|c|c|}
\hline Instituição de ensino superior & Localização & $N$ & $\%$ \\
\hline Universidade Federal da Paraíba/UFPB & Nordeste & 3 & 11.8 \\
\hline Universidade Estadual Paulista/UNESP & Sudeste & 4 & 14 \\
\hline Universidade Federal do Rio Grande do Norte/UFRN & Nordeste & 2 & 8 \\
\hline Universidade Federal do Ceará/UFCE & Nordeste & 2 & 8 \\
\hline Universidade Federal de São Carlos/Ufscar & Sudeste & 2 & 8 \\
\hline Universidade Federal do Espírito Santo/UfES & Sudeste & 2 & 8 \\
\hline Universidade de São Paulo/USP & Sudeste & 2 & 8 \\
\hline Universidade Federal do Rio Grande do Sul/UFRS & Sul & 1 & 3.8 \\
\hline Universidade Estadual do Rio de Janeiro/UERJ & Sudeste & 1 & 3.8 \\
\hline Universidade Federal de Santa Maria/UFSM & Sul & 1 & 3.8 \\
\hline Universidade Federal Sergipe/UFS & Nordeste & 1 & 3.8 \\
\hline Universidade Federal do Piaui/UFPI & Nordeste & 1 & 3.8 \\
\hline Universidade Estadual do Ceará/UECE & Nordeste & 1 & 3.8 \\
\hline Universidade Federal de Uberlândia/UFU & Sudeste & 1 & 3.8 \\
\hline Universidade Federal do Pará/UFPA & Norte & 1 & 3.8 \\
\hline \multirow[t]{2}{*}{ Universidade de Brasília/UNB } & Centro-Oeste & 1 & 3.8 \\
\hline & Total & 26 & 100 \\
\hline
\end{tabular}

Fonte: Banco de Teses da CAPES.

Tabela 3. Distribuição dos trabalhos por instituição - Portugal

\begin{tabular}{|l|l|c|c|}
\hline \multicolumn{1}{|c|}{ Instituição de ensino superior } & \multicolumn{1}{|c|}{ Localização } & N & \% \\
\hline Universidade da Madeira & llhas & 2 & 40 \\
\hline Universidade de Aveiro litoral & Norte & 1 & 20 \\
\hline Universidade de Trás os Montes e Alto Douro interior & Norte & 1 & 20 \\
\hline Universidade do Algarve & Sul & $\mathbf{5}$ & $\mathbf{1 0 0}$ \\
\hline & Total & 20 \\
\hline
\end{tabular}

Fonte: Teses do RCAAP, Repositórios Cientificos das Universidades públicas portuguesas e RENATES. 
Tabela 4. Produções selecionadas por autor, nível, orientador(a), instituição/programa e ano (Brasil)

\begin{tabular}{|c|c|c|c|c|}
\hline Autor & Nível & Orientador(a) & Instituição/Programa & Ano \\
\hline P1- Rossetto, E. & $\mathrm{D}$ & Claudio R. Baptista & UFRS / Educação & 2009 \\
\hline P2- Morejón, K. & $\mathrm{D}$ & Eucia B. L. Petean & USP / Psicologia & 2009 \\
\hline P3- Oliveira, C. B. & $\mathrm{D}$ & Raquel M. Villardi & UERJ / Políticas Públicas e Formação Humana & 2009 \\
\hline P4- Albino, I. B & $M$ & Francisco R. L. V. de Melo & UFRN / Educação & 2010 \\
\hline P5- Silva, A. C. B. & $M^{*}$ & Francisco H. da S. Frota & UECE / Planejamento e Políticas Públicas & 2010 \\
\hline PG- Melo, I. S. C. & $M$ & Jefferson F. Alves & UFRN / Educação & 2011 \\
\hline P7-Soares, A. C. S. & $\mathrm{D}$ & Ana Karina M. de Lira & UFCE / Educação & 2011 \\
\hline P8- CAStro, S. F. & $\mathrm{D}$ & Maria Amelia Almeida & UFscar / Educação Especial & 2011 \\
\hline P9- Watzlawick, J. A. A. & $M$ & Maria Alcione Munhóz & UFSM / Educação & 2011 \\
\hline P10- Borges, M. A. & $M$ & Alberto A. Gomes & UNESP / Educação & 2011 \\
\hline P11- Benevides, M. C. & $M$ & Tania Vicente Viana & UFCE / Educação & 2011 \\
\hline P12- Azevedo, M. C. & $M$ & Janine M. C. Rodrigues & UFPB / Educação & 2012 \\
\hline P13-Santos, A. C. & $M$ & Veronica dos R.M. Souza & UFSE / Educação & 2012 \\
\hline P14- Cruz, R. L. & $M$ & Janine M. C. Rodrigues & UFPB / Educação & 2012 \\
\hline P15- Santos, C. S. & $\mathrm{D}$ & Mara Rúbia A. Marques & UFU / Educação & 2013 \\
\hline P16-BRedA, D. C. & $M$ & Maria A. S. C. Barreto & UFES / Educação & 2013 \\
\hline P17-SouzA, H. L. & $M$ & Maria A. S. C. Barreto & UFES / Educação & 2013 \\
\hline P18-RODRIGUES, R. P. & $M$ & Ana Valéria M. F. Lustosa & UFPI / Educação & 2013 \\
\hline P19-SILVA, J.S.S. & $M$ & Maria E. P. de Carvalho & UFPB / Educação & 2014 \\
\hline P2O- CORRÊA, P. M. & $\mathrm{D}$ & Eduardo José Manzini & UNESP / Educação & 2014 \\
\hline P21- LIMEIRA, C. S. & $M$ & Genylton O. R. da Rocha & UFPA / Educação & 2014 \\
\hline P22- BRanco, A. P. S. C. & $M$ & Lúcia Pereira Leite & UNESP / Psicologia do Desen-volvimento e Aprendizagem & 2015 \\
\hline P23-BAÚ, M. A. & M & Eduardo José Manzini & UNESP / Educação & 2015 \\
\hline P24-ZAMPAR, J. A. & $M$ & Tânia Maria S. de Rose & UFscar / Educação Especial & 2015 \\
\hline P25-Carvalho, C. L. C. & M & Edson Luiz Riccio & USP / Controladoria e Contabi-lidade & 2015 \\
\hline P26- FERNANDES, A. C. R. F. & $M$ & Maria Cláudia Santos Lopes de Oliveira & UNB / Processos de Desenvolvi-mento Humano e Saúde & 2015 \\
\hline
\end{tabular}

Fonte: Banco de Teses da CAPES.

*Mestrado Profissionalizante. 


\section{Tabela 5. Produções selecionadas por autor, nível, orientador(a), instituição/programa e ano (Portugal)}

\begin{tabular}{|l|c|l|l|l|}
\hline \multicolumn{1}{|c|}{ Autor } & Nível & Orientador(a) & Ano \\
\hline P27- Abreu, S. M. V. A & M & Ana Maria P. Antunes & Universidade da Madeira/Psicologia da Educação \\
\hline P28- Marçal, T. L. & $M$ & Inês Maria Henriques Guedes de Oliveira & Universidade de Aveiro/ Ciências da Educaçao \\
\hline P29- França, S. D. & D & Maria Isabel Barros Morais Costa & Universidade de Trás os Montes e Alto Douro/Ciências da Educação & 2014 \\
\hline P30- Santos, E. M. F. & $M$ & Maria Manuela Bento Gonçalves & Universidade de Aveiro/Ciências da Educação \\
\hline P31- Silva, L. F. L. S. & $M$ & António Fragoso & Universidade do Algarve/ Educação Especial \\
\hline
\end{tabular}

Fonte: Repositórios Científicos das Universidades públicas portuguesas e RENATES.

\section{Caracterização temática}

Outro aspecto analisado refere-se aos temas das dissertações e teses selecionadas para o estudo. Foram abordados diferentes temas, porém todos trataram de questões de relevância para a inclusão das pessoas com deficiência no ensino superior (anexo 1).

De acordo com os títulos, no que se refere à categorização temática, após análise de conteúdo foram definidas as seguintes categorias: Acessibilidade/Ingresso/Permanência $(\mathrm{n}=14)$; Políticas de Inclusão (n = 9); Percepção/Vozes/Representações $(\mathrm{n}=6)$; Aprendizagem $(n=1)$; e Transições $(n=1)$ (tabela 6). Assinale-se contudo que, independente do tema abordado, os estudantes com deficiência tiveram vez e voz para se expressarem enquanto participantes das pesquisas. A análise permite constatar que, nas produções científicas se tem vindo a privilegiar, prioritariamente no Brasil as questões relacionadas com a acessibilidade, o ingresso e a permanência $(n=12 ; 46 \%)$, seguida das questões mais focalizadas nas políticas inclusivas $(n=9 ; 34.5 \%)$. Em Portugal, as temáticas das produções identificadas centram-se sobretudo nas políticas inclusivas $(n=3 ; 60 \%)$. Estes dados corroboram o fato de que no Brasil a existência da legislação parece já ter permitido que os investigadores se focalizem prioritariamente mais com a operacionalização das políticas inclusivas que favorecem as questões da acessibilidade, do ingresso e da permanência, enquanto em Portugal a inexistência de uma legislação adequada a este nível de ensino, leva a que ainda se focalize mais as questões de política inclusiva mais geral.

A análise categorial às palavras-chave revela uma maior heterogeneidade nos conceitos selecionados pelos investigadores no Brasil, espelhando uma investigação mais aprofundada e alargada. Tendo em atenção a desproporcionalidade existente relativa ao número de produções, assinale-se que foram encontradas trinta e três categorias para as produções brasileiras, sendo que para Portugal se constatou uma maior focalização nas palavras-chave, tendo-se encontrado cinco categorias (tabela 7).

A análise aos dados permite ainda referir que, em ambos os países os investigadores utilizaram prioritariamente como palavras-chave conceitos mais gerais como ensino superior (Brasil-19\%; Portugal, 31.5\%), Educação Inclusiva (Brasil-13\%; Portugal, 37.5\%), Pessoas ou Estudantes com deficiência (Brasil-13\%; Portugal, 12.5\%) (tabela 7). 
Tabela 6. Categorização temática dos títulos das dissertações e teses (Brasil e Portugal)

\begin{tabular}{|c|c|c|c|c|c|c|}
\hline \multirow{2}{*}{ Categorias } & \multicolumn{3}{|c|}{ Brasil } & \multicolumn{3}{|c|}{ Portugal } \\
\hline & Produções & $n$ & $\%$ & Produções & $n$ & $\%$ \\
\hline Acessibilidade/Ingresso/Permanência & $\begin{array}{l}\text { P2, P4, P6, P7, P8, P13, } \\
\text { P19, P20, P21, P22, P23 }\end{array}$ & 11 & 42 & P27, P29, P30 & 3 & 60 \\
\hline Políticas de inclusão & $\begin{array}{l}\text { P3, P5, P9, P10, P12, } \\
\text { P15, P16, P17 }\end{array}$ & 8 & 31 & P28 & 1 & 20 \\
\hline Percepção/Vozes/Representações & $\begin{array}{l}\text { P1, P14, P18, P24, P25, } \\
\text { P26 }\end{array}$ & 6 & 23 & - & - & - \\
\hline Aprendizagem & P11 & 1 & 4 & - & - & - \\
\hline Transições & - & - & - & P31 & 1 & 20 \\
\hline & Total & 26 & 100 & Total & 5 & 100 \\
\hline
\end{tabular}

Fonte: Teses da CAPES, RCAAP, Repositórios Científicos das Universidades públicas portuguesas e RENATES.

Tabela 7. Categorização temática das palavras-chave das dissertações e teses (Brasil e Portugal)

\begin{tabular}{|c|c|c|c|c|}
\hline \multirow{2}{*}{ Categorias } & \multicolumn{2}{|c|}{ Brasil } & \multicolumn{2}{|c|}{ Portugal } \\
\hline & $n$ & $\%$ & $n$ & $\%$ \\
\hline Ensino superior/Universidade & 23 & 19 & 5 & 31.5 \\
\hline Educação inclusiva/Inclusão & 16 & 13 & 6 & 37.5 \\
\hline Pessoas com deficiência/Estudante com deficiência & 15 & 13 & 2 & 12.5 \\
\hline Acesso/ Acessibilidade & 12 & 11 & & \\
\hline Políticas públicas de inclusão & 5 & 4 & & \\
\hline Deficiência visual/Alunos com deficiência visual & 5 & 4 & & \\
\hline Pessoas com necessidades especiais/Pessoas com necessidades educacionais especiais & 3 & 3 & 2 & 12.5 \\
\hline Políticas de ações afirmativas na educação superior & 3 & 3 & & \\
\hline Educação especial & 3 & 3 & & \\
\hline Satisfação & 2 & 2 & & \\
\hline Educação & 2 & 2 & & \\
\hline Avaliação/Avaliação das aprendizagens & 2 & 2 & & \\
\hline
\end{tabular}




\begin{tabular}{|c|c|c|c|c|}
\hline Histórias de vida & 1 & 1 & & \\
\hline Trajetórias de desenvolvimento & 1 & 1 & & \\
\hline Abordagem histórico-cultural & 1 & 1 & & \\
\hline Pensamento sistémico & 1 & 1 & & \\
\hline Ingresso e permanência & 1 & 1 & 1 & 6 \\
\hline Processos de significação & 1 & 1 & & \\
\hline Educação musical & 1 & 1 & & \\
\hline Cotas & 1 & 1 & & \\
\hline Deficiência física & 1 & 1 & & \\
\hline Surdez & 1 & 1 & & \\
\hline Representações sociais & 1 & 1 & & \\
\hline Gestão social & 1 & 1 & & \\
\hline Núcleo de acessibilidade & 1 & 1 & & \\
\hline Pós-graduação & 1 & 1 & & \\
\hline Estudos culturais de deficiência & 1 & 1 & & \\
\hline Integração à universidade & 1 & 1 & & \\
\hline Estereótipos & 1 & 1 & & \\
\hline Retratos & 1 & 1 & & \\
\hline História de vida & 1 & 1 & & \\
\hline Autenticidade & 1 & 1 & & \\
\hline Transição & 1 & 1 & & \\
\hline Total & 112 & 100 & 16 & 100 \\
\hline
\end{tabular}

Fonte: Teses da CAPES, RCAAP, Repositórios Científicos das Universidades públicas portuguesas e RENATES. 


\section{Caracterização metodológica das produções científicas}

Em relação aos aspectos metodológicos dos trabalhos que fazem parte deste estudo (Brasil e Portugal) constatámos não existirem diferenças significativas nas opções dos investigadores. Assim, os autores das 31 produções assumem que a investigação é qualitativa $(100 \%)$, sendo que seis $(18 \%)$ acrescentam que optaram por uma metodologia mista, combinando a análise qualitativa com análise quantitativa (P2; P8; P13; P23; P27; P30). Referem ainda, vinte e oito que a pesquisa é de tipo exploratória $(90 \%)$, sendo que doze $(39 \%)$ acrescentam ser uma investigação de tipo estudo de caso. Apenas um investigador assinala que a sua pesquisa é de carácter longitudinal (P26), e um outro refere que utilizou a metodologia investigação-ação participativa (P28).

Como instrumentos privilegiados também se verifica existir uma grande homogeneidade nos dois países, concluindo-se que todos os investigadores utilizam a entrevista semiestruturada para recolher as vozes e experiências dos participantes, não obstante alguns acrescentem outros instrumentos de pesquisa. Neste sentido, nove investigadores $(29 \%)$ referem a utilização de análise documental (P3; P6; P7; P8; P9; P19; P29; P30; P31), quatro (13\%) acrescentam respectivamente o questionário (P5; P10; P11; P31), e a observação (P4; P6; P7; P8), sendo que um (3\%) assinala ainda o uso de pesquisa bibliográfica (P3) e do Questionário de Vivências Acadêmicas (P24; P27). São também referidas a utilização de registros fotográficos (P6), artefatos físicos (P6), cartas (P26), as técnicas de shadowing (P19), notas de terreno (P28), conversas informais (P28) e dos retratos (P28) (anexo 2).

Relativamente aos participantes a análise constata também alguma variabilidade nos dois países. Assim, dos 259 estudantes que dão voz nas produções científicas brasileiras, existem investigações que dão voz apenas a um estudo de caso, nomeadamente cegos (P6 e P12) e surdos (P16). As restantes produções incluem diversas deficiências, salientando-se contudo uma maior visibilidade das vozes de estudantes com deficiência física $(n=106 ; 41 \%)$, baixa visão $(n=68$; $26 \%)$, e estudantes cegos $(n=31 ; 12 \%)$. Com uma menor expressividade encontram-se testemunhos de estudantes com deficiência auditiva $(n=23 ; 9 \%)$ e surdos $(n=22 ; 8 \%)$, e por último é dada voz aos estudantes com multideficiência $(n=2 ; 0.7 \%)$, déficit de atenção $(n=2 ; 0.7 \%)$, deficiência intelectual $(n=1 ; 0.3 \%)$ e dislexia $(n=1 ; 0.3 \%)$.

Em Portugal, dos quarenta e um estudantes ouvidos, a análise permite constatar que prioritariamente é dada voz aos estudantes com deficiência motora $(n=31 ; 76 \%)$, seguindo-se os estudantes com multideficiência $(n=2 ; 5 \%)$ e déficit de atenção $(n=2 ; 5 \%)$ e com ainda menor visibilidade a voz de estudantes com daltonismo $(n=1 ; 2 \%)$, e cego $(n=1 ; 2 \%)$.

Esta análise permite concluir que, no Brasil a investigação recolheu testemunhos de uma diversidade de estudantes com deficiência superior à que encontramos em Portugal, sendo que os dados parecem sugerir que, não só o número de estudantes com deficiência que chegam ao ensino superior é ainda muito reduzido em Portugal, como existe ainda uma fraca representatividade dos diferentes tipos de deficiência neste nível de ensino. Estes resultados vão ao encontro das conclusões do estudo realizado pelo Grupo de Trabalho de Apoio ao Estudante com Deficiência no Ensino Superior (GTAEDES) em 2014, em colaboração com a Direção Geral do Ensino Superior. Segundo este estudo em 2013/2014, os estudantes que tinham sido sinalizados totalizavam 1318 alunos distribuídos no ensino superior público e privado. De assinalar que, em Portugal, é referida a existência por parte de alguns estudantes de receio do estigma da deficiência, sendo que alguns acabam por rejeitar a sinalização quando entram nas instituições de ensino superior (Curado e Oliveira, 2010). A fraca representatividade dos diversos tipos de deficiência e a prevalência da deficiência motora é também assinalada nos estudos de Curado e Oliveira (2010) e Martins et al. (2015). 


\section{Experiências dos estudantes com deficiência nas universidades do Brasil e de Portugal a partir das produções académicas}

Tendo como objetivo destacar os aspectos mais relevantes, apresenta-se seguidamente uma visão panorâmica dos estudos identificados que tiveram no seu contexto experiências de estudantes com deficiência no ensino superior no Brasil e em Portugal.

No seu estudo, Rossetto (2009) investigou as trajetórias de estudantes surdos e com deficiência visual. Conclui que os apoios (da família, colegas, docentes, ou dos serviços de apoio na instituição), a disposição interna dos sujeitos e os mecanismos de compensação constituem elementos propulsores para a superação das dificuldades. Situação semelhante é identificada nos estudos de Soares (2011), de Abreu (2013), de Silva (2014) e de Rodrigues (2013); mais do que as ações inclusivas o sucesso acadêmico destes estudantes é atribuído ao esforço individual e aos apoios que recebem da família, colegas e de alguns docentes.

A maior parte dos estudos reconhece que, apesar dos avanços legais da educação inclusiva serem inegáveis, há muito ainda por fazer no atendimento aos alunos com deficiência (Albino, 2010; Branco, 2015; Cruz, 2012; Morejón, 2009; Santos, 2014) como provam as dificuldades que os alunos referem enfrentar, identificadas nos estudos analisados:

a) Nas barreiras arquitetônicas e de acessibilidade física (Abreu, 2013; Albino, 2010; Azevedo, 2012; Benevides, 2011; Borges, 2011; Branco, 2015; Castro, 2011; Corrêa, 2014; Cruz, 2012; Limeira, 2014; Marçal, 2013; Melo, 2011; Santos, 2012; Silva, 2014; Souza, 2013; Zampar, 2015).

b) Nas barreiras atitudinais e pedagógicas (Abreu, 2013; Albino, 2010; Azevedo, 2012; Castro, 2011; Benevides, 2011; Borges, 2011; Branco, 2015; Corrêa, 2014; Cruz, 2012; Marçal, 2013;
Melo, 2011; Santos, 2013; Silva, 2010; Silva, 2014; Zampar, 2015).

c) Na falta de recursos e de profissionais especializados (e.g. intérprete de libras) para garantir a participação nas atividades acadêmicas e sociais (Benevides, 2011; Branco, 2015; França, 2014; Marçal, 2013; Santos, 2013; Silva, 2014; Souza, 2013; Zampar, 2015).

d) Na falta de preparação dos docentes e funcionários (Carvalho, 2015; Corrêa, 2014; Santos, 2012; Silva, 2014).

e) Na falta de conhecimento dos próprios estudantes sobre a legislação e os apoios que a instituição pode oferecer ou que podem solicitar (Abreu, 2013; Corrêa, 2014).

f) Na ausência de uma política de inclusão institucional e de serviço de apoio que assegure a continuidade dos estudos, qualidade de vida e bem-estar social no contexto universitário (Breda, 2013; Watzlawick, 2011; Souza, 2013).

g) Falta de medidas legais e de políticas inclusivas nacionais (no caso português) (Santos, 2014).

Segundo os testemunhos destes estudantes as dificuldades referidas são, contudo amenizadas pelo apoio e solidariedade dos colegas (Carvalho, 2015; Rodrigues, 2013; Santos, 2013; Silva, 2014; Zampar, 2015), da família (Silva, 2014), do pessoal técnico administrativo (Santos, 2013), pelo avanço das tecnologias e sobretudo pelo esforço individual de cada estudante (Rodrigues, 2013).

Já Baú (2015) ao estudar as condições de acessibilidade e a satisfação de estudantes com deficiência física e auditiva, os estudantes inquiridos revelam uma boa satisfação operacional, psicoafetiva, estrutural e atitudinal no que se refere às questões inclusivas e de acessibilidade na universidade.

Visando analisar as políticas de acesso e permanência para os estudantes com deficiência no Brasil e em Portugal, Santos (2013) efetuou uma análise sobre a política e legislação educacional e pesquisa em 
quatro universidades (duas em cada país). Constata que estes avaliam de forma positiva o processo seletivo para ingresso nas instituições; avaliação idêntica é feita pelos estudantes no estudo de Corrêa (2014) e de Souza (2013).

Com base nos testemunhos de estudantes com deficiência que entraram pelo sistema de cotas, Watzlawick (2011) procurou analisar o processo de inclusão educacional. Os resultados sinalizam a importância deste mecanismo para garantir o acesso ao ensino superior. Também, Santos (2014), tendo como objetivo analisar a inclusão de estudantes com necessidades educativas especiais, conclui que o contingente especial para acesso ao ensino superior é um importante suporte.

Por seu lado, Oliveira (2009) nas conclusões da sua investigação com estudantes que entraram pelo sistema de cotas, aponta para uma relativa invisibilidade destes estudantes que apresentam escassa participação e enfrentam ainda problemas relacionados com a pedagogia acadêmica. No reconhecimento desta situação, a maioria dos estudantes com deficiência visual no estudo realizado por Azevedo (2012), sugere serem ouvidos, para que as suas necessidades sejam atendidas. E, é a voz dos estudantes inquiridos que sugere ainda como recomendações para melhorar o atendimento e a permanência dos alunos:

- No estudo de Carvalho (2015), a melhoria dos serviços de apoio, a divulgação dos serviços disponibilizados, a capacitação dos professores, a sinalização dos ambientes e o investimento em tecnologia.

- No estudo de Santos (2014), os recursos, as acessibilidades físicas/estruturais e culturais/atitudinais, bem como os apoios disponibilizados.

Castro (2011) avaliou 13 universidades públicas brasileiras com o objetivo de identificar ações e iniciativas institucionais direcionadas para o ingresso e permanência de pessoas com deficiência visual, física, intelectual e surdos. Os resultados indicam estágios diferenciados de ações inclusivas, ainda insuficientes para garantir a permanência e a participação destes estudantes.

O estudo de Fernandes (2015) teve como objetivo analisar as trajetórias de estudantes com deficiência, no ensino superior no Brasil e em Portugal. A investigadora constatou que estes estudantes enfrentam importantes desafios e necessitam ultrapassar obstáculos cotidianos, nomeadamente barreiras ambientais e simbólicas, inadequação ou insuficiência de serviços, estruturas arquitetônicas inadequadas, preconceitos dos professores, invisibilidade das suas necessidades e baixas prioridades no que se refere a investimentos e políticas institucionais deixando as suas necessidades específicas não atendidas.

\section{Considerações finais}

A análise das políticas internacionais revela uma consciencialização crescente sobre os direitos das pessoas com deficiência, justificando-se o interesse pela educação inclusiva no ensino superior. Não obstante, continua a verificar-se uma grande invisibilidade destes estudantes neste grau de ensino. $\mathrm{O}$ desenvolvimento de investigações em que é dada voz aos estudantes com deficiência é crucial, pois permite ouvir as suas próprias questões e dificuldades. Efetivamente, continuamos a assistir a um grande isolamento social da pessoa com deficiência, o que em parte também poderá contribuir para justificar o reduzido número de investigações sobre as representações e percepções destas pessoas. Ouvir o que têm a dizer, as suas dificuldades e, sobretudo, as sugestões que apresentam pode constituir-se uma valiosa contribuição para melhorar as práticas inclusivas no ensino superior.

Embora timidamente, alguns investigadores começam a analisar o que pensam, o que sentem e o que dizem estes estudantes que chegam ao ensino superior. Neste sentido, o presente estudo constituiu uma reflexão sobre a atenção que a comunidade 
científica tem vindo a dar na última década a esta população estudantil, pretendendo-se analisar a produção científica no Brasil e em Portugal que aborda as experiências e as vozes destes estudantes.

Da análise realizada às dissertações de mestrado e de doutoramento produzidas no Brasil e em Portugal, no período de 2008 a 2015, é possível concluir que, se por um lado é crescente o número de estudantes com deficiência que vem ingressando no ensino superior, a investigação neste âmbito é ainda muito embrionária e, muitas vezes negligenciada pela comunidade científica acadêmica.

Os resultados do presente estudo corroboram a investigação desenvolvida por Oliveira et al. (2016) que teve como propósito analisar a produção científica sobre a educação inclusiva no ensino superior. Através de uma revisão da literatura realizada entre os anos 2005 e 2014, estes investigadores concluíram que "as publicações sobre a educação inclusiva no ensino superior têm sido tênues, demonstrando que ainda há muito a avançar nesse assunto" (Oliveira et al., 2016: 299). Acrescentam ainda que a comunidade científica tem vindo a dar uma maior atenção à temática da educação inclusiva no que se refere às crianças, sendo que a atenção sobre pessoas adultas com "necessidades especiais" tem sido mais direcionada para a assistência em saúde e não para a educação inclusiva no ensino superior.

O estudo também parece sinalizar para uma possível influência da normatização jurídica em termos de política e legislação sobre os direitos das pessoas com deficiência no ensino superior como desencadeador da produção do conhecimento na área, uma vez que torna visível a discussão da problemática e o que está vigente nas políticas educacionais de cada país. Essa constatação é levantada a partir da pesquisa realizada onde se percebe nitidamente essa relação entre a produção stricto sensu produzida no Brasil e em Portugal, sem desconsiderar outras peculiaridades entre os países investigados (dimensão geográfica, quantidade de universidades e programas de pós-graduação, entre outras).
Estes resultados devem merecer a atenção crítica dos governos e decisores políticos, bem como da comunidade acadêmica e científica, uma vez que em ambos os países e, não obstante os estágios diferentes de medidas legislativas, os estudantes inquiridos manifestam que ainda existe muito para ser feito para que a inclusão seja uma realidade. A voz destes estudantes revela que as ações inclusivas ainda são insuficientes para garantir a sua permanência e participação com qualidade de vida e bem-estar no contexto da vida universitária. De fato, continuam a ser assinaladas a presença de diversas barreiras arquitetônicas, comunicacionais, pedagógicas e atitudinais em ambos os países.

Muitos são os estudantes que referem que, não obstante as boas vontades e o esforço que sentem estar a ser feito, a maior parte dos docentes não estão preparados para lidar com alunos com deficiências. Embora muito frequentemente a maior justificativa para a não inclusão seja a estrutura física das instituições de ensino, diversos estudos têm vindo a revelar que a maior barreira para a inclusão escolar é, fundamentalmente, a falta de preparação dos docentes e dos gestores, que não possuem nem sensibilidade nem formação (Martins et al., 2016).

Estes estudantes alertam ainda para que, na maior parte das vezes, são os apoios da família e dos colegas, bem como a sua força e disposição interna os determinantes para que consigam superar com sucesso as adversidades que continuam a encontrar no percurso universitário. Efetivamente, a permanência dos estudantes com deficiência no ensino superior pode resultar em fracasso atendendo às diversas barreiras que continuam a existir, denunciando um ambiente potencializador da manutenção da exclusão. Assim, é urgente que as instituições de ensino superior mudem as suas culturas e práticas de forma a garantir uma educação adequada a todas às pessoas da sociedade, procurando eliminar todo o tipo de processos que levam à exclusão social (Barton, 2009). 
Tendo como referencial as experiências e as vozes destes estudantes alicerçadas na legitimidade de participar nas discussões e tomadas de decisão que dizem respeito à sua vida, espera-se que estes indicadores possam suscitar importantes reflexões e sobretudo possam guiar a necessária transformação das instituições educativas contribuindo para a melhoria

\section{Referencias}

Abreu, S. (2013), "Alunos com necessidades educativas especiais: estudo exploratório sobre a inclusão no ensino superior", Dissertação de Mestrado em Psicologia da Educação (67f.), Madeira, Portugal, Universidade da Madeira.

Alarcón, M. S., M. R. Lissi, D. M. Polizzi, M. Z. Pavez y A. M. H. Loret, (2013), "La inclusión en la educación superior: desde la voz de estudiantes chilenos con discapacidad", em Revista Iberoamericana de Educación, vol. 63, pp. 77- 98.

Albino, I. B. (2010), "Acesso e permanência na Universidade Federal do Rio Grande do Norte sob o ponto de vista do docente e do estudante com deficiência”, Dissertação de Mestrado em Educação (205 f), Natal, Brasil, Universidade Federal do Rio Grande do Norte.

Azevedo, M. C. A. (2012), "Políticas de Acesso para Discentes com Deficiência Visual no Ensino Superior: um estudo de caso", Dissertação de Mestrado em Educação (140 f.), Brasil, Universidade Federal da Paraíba, João Pessoa.

Bardin, L. (1999), Análise de conteúdo, Lisboa, Edições 70.

Barnes, C. (2003), "What a difference a decade makes: reflections on doing 'emancipatory' disability research", em Disability and Society, vol. 18, núm. 1, pp. 3-17.

Barton, L. (2009), "Estudios sobre discapacidad y la búsqueda de la inclusividad", em Revista de Educación, da qualidade da resposta aos desafios da inclusão no ensino superior.

\section{Agradecimentos}

Os autores agradecem à CAPES (P-99999.002554 /2015-01) o apoio financeiro recebido para o desenvolvimento deste trabalho.

vol. 349, pp. 137-152.

Baú, M. A. (2015), "Avaliação da acessibilidade no ensino superior: UTFPR-Câmpus Medianeira”, Dissertação de Mestrado em Educação (123f.), Marília, Brasil, Universidade Estadual Paulista.

Benevides, M. C. (2011), "Avaliação da aprendizagem de alunos com deficiência: estudo de caso em uma instituição superior da rede pública”, Dissertação de Mestrado em Educação (172 f.), Fortaleza, Brasil, Universidade Federal do Ceará.

Borges, M. A. (2011), "A inclusão de alunos com deficiência em cursos presenciais de graduação da Universidade de Juiz de Fora", Dissertação de Mestrado em Educação (142 f.), Brasil, Universidade Estadual Paulista Júlio de Mesquita Filho.

Booth, T. y M. Ainscow (2002), Index for Inclusion - Developing Learning Participation in School, Londres, Centre for Studies on Inclusive Education (CSIE), <http://www. eenet.org.uk/resources/docs/Index\%20English.pdf> [Consulta: novembro de 2015].

Breda, D. C. (2013), "A inclusão no ensino superior: um estudante surdo no Programa de Pós-graduação em Educação", Dissertação de Mestrado em Educação (182f.), Vitória, Brasil, Universidade Federal do Espírito Santo.

Branco, A. P. (2015), "Análise das condições de acessibilidade no ensino superior: um estudo com Pós- 
Graduandos", Dissertação de Mestrado em Psicologia do Desenvolvimento e Aprendizagem (164f.), Bauru, Brasil, Universidade Estadual Paulista.

Cabral, L. S. A. y F. R. L. V. Melo (2017), "Entre a normatização e a legitimação do acesso, participação e formação do público-alvo da educação especial em instituições de ensino superior brasileiras", em Educar, vol. 33, núm. especial 3, pp. 55-70.

Carvalho, G. L. C. (2015), "Pessoas com deficiência no ensino superior: percepções dos alunos", Dissertação de Mestrado em Controladoria e Contabilidade (95f.), São Paulo, Brasil, Universidade de São Paulo.

Castro, S. F. de (2011), "Ingresso e permanência de alunos com deficiência em universidades públicas brasileiras", Tese de Doutorado em Educação Especial (245f.), São Carlos, Brasil, Universidade Federal de São Carlos.

Corrêa, P. M. (2014), "Acessibilidade no ensino superior: instrumento para avaliação, satisfação dos alunos com deficiência e percepção de coordenadores de cursos", Tese de Doutorado em Educação (281f.), Marília, Brasil, Universidade Estadual Paulista.

Cruz, R. L. (2012), "Inclusão no ensino superior: um estudo das representações sócias dos acadêmicos com deficiência visual da UFPB”, Dissertação de Mestrado em Educação (130f.), Brasil, Universidade Federal Paraíba, João Pessoa.

Curado, A. P. y V. Oliveira (2010), "Estudantes com necessidades educativas especiais na Universidade de Lisboa", Lisboa, Gabinete de Garantia da Qualidade. Observatório dos Percursos dos Estudantes, Universidade de Lisboa, pp. 24-36, <http://www. ulisboa.pt/wp-content/uploads/MenuEstudar/ Necessidades_Educativas_Especiais/Publicacao_ Estudantes_NEE.pdf> [Consulta: setembro de 2015].

Decreto-Lei 3, 7 de Janeiro de 2008 (2008), Diário da República, I Série. no 4/7, pp. 154-164, <https:// dre.tretas.org/pdfs/2008/01/07/dre-225887.pdf> [Consulta: novembro de 2015].

Decreto-6.571, 17 de setembro de 2008 (2008), Dispõe sobre o atendimento educacional especializado, regulamenta o parágrafo único do art. 60 da Lei 9.394, de 20 de dezembro de 1996, e acrescenta dispositivo ao Decreto-6.253, 13 de novembro de 2007, Brasília, DF, Presidência da República.

Decreto n. ${ }^{\circ}$ 7.611, de 17 de novembro de 2011 (2011), Dispõe sobre a educação especial, o atendimento educacional especializado e dá outras providências, Brasília, DF, Presidência da República.

Diez, A. M. y V. M., Romo, (2011), "La universidad a análisis: las voces del alumnado con discapacidad", em Revista de Enseñanza Universitaria, vol. 37, pp. 23-35.

França, S. D. (2014), "Inclusão de alunos com NEE no ensino superior: um estudo de caso na universidade Estadual de montes claros (UNIMONTES)", Tese de Doutorado em Ciências da Educação (207f.), Portugal, Universidade de Trás os Montes e Alto Douro.

Fernandes, A. C. R. F. (2015), "Dinâmicas de significação e trajetórias de desenvolvimento: experiências de estudantes com deficiência autodeclarada na universidade", Dissertação de Mestrado em Processos de Desenvolvimento Humano e Saúde (238f.), Brasília, Brasil, Universidade de Brasília.

Fontes, F. (2009), "Pessoas com deficiência e políticas sociais em Portugal: da caridade à cidadania social", em Revista Crítica de Ciências Sociais, vol. 86, pp. 73-93.

Gonçalves, T. G. G. L. y M. C. P. I., Hayashi, (2014), "Estudo bibliométrico sobre educação do campo para jovens e adultos deficientes", em Série-Estudos: Campo Grande, MS, vol. 38, jul./dez. 2014, pp. 129-149.

Grupo de Trabalho da Política Nacional de Educação Especial. (2008), "Política Nacional de Educação Especial na perspectiva da educação inclusiva", Brasília, <http://portal.mec.gov.br/index.php?option=com_ docman\&view $=$ download\&alias $=16690$-politicanacional-de-educacao-especial-na-perspectiva-daeducacao-inclusiva-05122014\&Itemid=30192> [Consulta: dezembro de 2015].

Hadjikakou, K. y D Hartas, (2008), "Higher education provision for students with disabilities in Cyprus", em Higher Education, vol. 55, núm. 1, pp. 103-119.

Harrison, M., L., M. Harrison, L. Hemingway, A. Sheldon, R. Pawson, y G. Barnes, (2009), "Evaluation 
of provision and support for disabled students in higher education", Bristol: The Higher Education Funding Council for England, <http://www.hefce.ac.uk/pubs/ rdreports/2009/rd24_09/> [Consulta: dezembro de 2015].

Kyriazopoulou, M. y H. Weber, (Eds.) (2009), "Desenvolvimento de um conjunto de indicadores para a educação inclusiva na Europa”, Odense, Denmark, European Agency for Development in Special Needs Education, <https://www.european-agency.org/sites/ default/files/development-of-a-set-of-indicators-forinclusive-education-in-europe_indicators-PT.pdf $>$ [Consulta: setembro de 2015].

Limeira, C. S., (2014), "Acessibilidade física e inclusão no ensino superior: um estudo de caso na UFPA", Dissertação de Mestrado em Educação (121f.), Belém, Brasil, Universidade Federal do Pará.

Luque-Parra, D. J., G. Rodríguez-Infante y M. J. LuqueRojas, (2014), "Adecuación del currículum al alumnado universitario con discapacidad: un estudio de caso", em Revista Iberoamericana de Educación Superior (RIES), México, UNAM-IISUE/Universia, vol. 13, pp. 101-116, <http://ries.universia.net/index.php/ries/ article/view/328> [Consulta: dezembro de 2015].

Marçal, T. L. (2013), "Inclusão no ensino superior: retratos de estudantes com deficiência", Dissertação de Mestrado em Ciências da Educação (207f.), Portugal, Universidade de Aveiro.

Marconi, M. A. y E. M. Lakatos, (2008), Fundamentos de metodologia científica, 7 ed., São Paulo, Atlas.

Márquez-Ramírez, G. (2015), “Los estudiantes universitarios con diversidad funcional visual. Sus retos", em Revista Iberoamericana de Educación Superior (RIES), UNAM-IISUE/Universia vol. 6, núm. 17, pp. 135-158, <https://ries.universia.net/article/ view/1456/estudiantes-universitarios-diversidadfuncional-visual-retos $>$ [Consulta: dezembro de 2015]. Martins, B. S., F. Fontes, P. Hespanha, y A. Berg, (2012), "A emancipação dos estudos da deficiência", em Revista Crítica de Ciências Sociais, vol. 98, pp. 45-63.

Martins, M. H. V. (2000), “Apoios Educativos e Práticas
Pedagógicas", em S. N. de Jesus y M. H. V. Martins, Escola Inclusiva e Apoios Educativos, pp. 11-27, Cadernos do CRIAP, Porto, Edições Asa.

Martins, M. H., Borges, M. L., Fonseca, H., Gonçalves, T., y J. Ferreira, (2015), "Estudantes não-tradicionais no ensino superior: investigar para guiar a mudança institucional", Relatório apresentado à Fundação para a Ciência e Tecnologia no âmbito do projeto PTDC/ IVC-PEC/4886/2012 (documento policopiado).

Martins, M. H., M. L. Borges, y T. Gonçalves, (2017), "Attitudes towards inclusion in higher education in a Portuguese university", em International fournal of Inclusive Education, <http://dx.doi.org/101080/13603116.2017.1377299> [Consulta: dezembro de 2017].

Melo, F. R. L. V. y M. H. Martins, (2016), "Legislação para estudantes com deficiência no ensino superior no Brasil e em Portugal: algumas reflexões", em Acta Scientiarum. Education, Maringá, vol. 38, núm. 3, July-Sept., 2016, pp. 259-269.

Melo, I. S. C. (2011), "Um estudante cego no curso de Licenciatura em Música na UFRN: Questões de acessibilidade curricular e física", Dissertação de Mestrado em Educação (146 f.), Natal, Brasil, Universidade Federal do Rio Grande do Norte.

Morejón, K. (2009), "O acesso e a acessibilidade de pessoas com deficiência no ensino superior público no Estado do Rio Grande do Sul”, Tese de Doutorado em Ciências (252 f.), Ribeirão Preto, Brasil, Universidade de São Paulo.

Oliveira, A. B. (2009), Ações afirmativas e inclusão sustentável de estudantes com limitações por deficiência no Ensino Superior, 223f., Tese de Doutorado em Políticas Públicas e Formação Humana, Rio de Janeiro, Brasil, Universidade Estadual do Rio de Janeiro.

Oliveira, R. Q. de, S. M. B. de Oliveira, N. A. de Oliveira, M. C. S. F. Trezza, I. B Ramos, y D. A. Freitas, (2016), "A Inclusão de Pessoas com Necessidades Especiais no Ensino Superior", em Revista Brasileira de Educação Especial, vol. 22, núm. 2, Abr.-Jun., 2016, pp. 299-314, <http://dx.doi.org/10.1590/S1413- 
65382216000200011> [Consulta: dezembro de 2015].

Oliver, M. (1992), "Changing the social relations of research production", em Disability, Handicap and Society, vol. 7, núm. 2, pp. 101-114.

Oliver, M. (1997), "Emancipatory research: realistic goal or impossible dream?", em Doing disability research, Leeds: The Disability Press, pp. 15-31. <http://disabilitystudies.leeds.ac.uk/files/library/Barnes-Chapter-2. pdf $>$ [Consulta: dezembro de 2015].

Oliver, M. y C. Barnes, (2012), "Back to the future: the world report on disability", em Disability and Society, vol. 27, núm. 4, June, pp. 123-131.

Organização das Nações Unidas (ONU) (2006), "Convenção sobre os Direitos das Pessoas com Deficiência", Doc. A/61/611, Nova Iorque.

Pereira, R. R., S. S. C. Silva, c. Faciola, F. A. R. Pontes y M. F. H Ramos (2016), "Inclusão de estudantes com deficiência no ensino superior: uma revisão sistemática", em Revista Educação Especial, vol. 29, núm. 54, pp. 147-160, Santa Maria, <http:// www.ufsm.br/revistaeducacaoespecial > <doi. org/10.5902/1984686X19898>, [Consulta: dezembro de 2015].

Organização Mundial da Saúde (2012), "Relatório Mundial sobre a Deficiência”, São Paulo, Governo de São Paulo, Secretaria dos Direitos da Pessoa com Deficiência.

Rigolin, C. C. D., C. R. M. Hayashi y M. C. P. I. Hayashi, (2013), "Métricas da participação feminina na ciência e na tecnologia no contexto dos INCTs: primeiras aproximações Liinc", em Revista Rio de Faneiro, vol. 9, pp. 143-170.

Rodrigues, R. P. (2013), "O Movimento inclusivo no ensino superior na perspectiva de alunos cegos", Dissertação de Mestrado em Educação (118f.), Teresina, Brasil, Universidade Federal do Piauí.

Rodriguez-Martin, A. y E. Alvarez-Arregui, (2014), "Estudiantes con discapacidad en la Universidad. Un estudio sobre su inclusión", em Revista Complutense de Educación, vol. 25, núm. 2, pp. 457-479.

Rossetto, E. (2009), "Sujeitos com Deficiência no Ensino
Superior: vozes e significados", Tese de Doutorado em Educação (234f.), Porto Alegre, Brasil, Universidade Federal do Rio Grande do Sul.

Runswick-Cole, K. (2011), "Time to end bias towards inclusive education?", em British Fournal of Special Education, vol. 38, núm. 3, pp. 112-119.

Santos, A. C. N. (2012), "Acessibilidade da pessoa dom deficiência física: o caso da Universidade Federal de Sergipe-Cidade Universitária Professor José Aloísio de Campos", Dissertação de Mestrado em Educação (147f.), Universidade Federal de Sergipe, São Cristóvão, Brasil.

Santos, C. S. (2013), "Políticas de acesso e permanência de alunos com deficiência em universidades brasileiras e portuguesas", Tese de Doutorado em Educação (389f.), Universidade Federal de Uberlândia, Uberlândia, Brasil.

Santos, E. M. (2014), "Ingresso e permanência de estudantes com NEE no Ensino Superior: um estudo qualitativo", Dissertação de Mestrado em Ciências da Educação (142f.), Portugal, Universidade de Aveiro.

Silva, L. F. L. (2014), "As Transições dos estudantes com Necessidades Educativas Especiais do Ensino Secundário para o Superior: um estudo de caso na Universidade do Algarve", Dissertação de Mestrado em Educação Especial (140f.), Portugal, Universidade do Algarve.

Silva, A. C. B. (2010), "Políticas públicas para inclusão e permanência de alunos com necessidades educacionais especiais no ensino superior: a experiência da Universidade do Estado do Pará", Dissertação de Mestrado Profissional em Planejamento e Politicas Públicas (99f.), Fortaleza, Brasil, Universidade Estadual do Ceará.

Silva, J. S. S. (2014), "Acessibilidade, barreiras e superação: estudo de caso de experiências de estudantes com deficiência na educação superior”, Dissertação de Mestrado em Educação (242f.), João Pessoa, Brasil, Universidade Federal da Paraíba.

Soares, A. C. S. (2011), "A inclusão de alunos com deficiência visual na Universidade Federal do Ceará: 
ingresso e permanência na ótica dos alunos, docentes e administradores", Tese de Doutorado em Educação (240 f.), Fortaleza, Brasil, Universidade Federal do Ceará.

Souza, H. L. (2013), "Para lembrar que você existe: um estudo de caso sobre as politicas de inclusão para os estudantes com deficiência na Universidade Federal do Espírito Santo", Dissertação de Mestrado em Educação (148f.), Brasil, Universidade Federal do Espirito Santo Vitória.

UNESCO (1994), "The Salamanca statement on principles, policy and practice in special needs education", Salamanca, World Conference on Special Needs Education, Access and Quality", UNESCO.

Watzlawick, J. A. A. (2011), "As (im) possibilidades da inclusão na educação superior”, Dissertação de Mestrado em Educação (167f.), Santa Maria, Brasil, Universidade Federal de Santa Maria.

Zampar, J. A. S. (2015), "Integração à universidade na percepção de estudantes com deficiência, Dissertação de Mestrado em Educação Especial (103f.), São Carlos, Brasil, Universidade Federal de São Carlos.

\section{Cómo citar este artículo:}

Lins-Vieira de Melo Francisco-Ricardo, Maria-Helena Martins, Maria-Leonor Borges y Teresa Gonçalves (2019), "As vozes dos estudantes universitários com deficiência nas instituições públicas de ensino superior no Brasil e em Portugal (2008 - 2015)", en Revista Iberoamericana de Educación Superior (RIES), México, UNAM-IISUE/Universia, vol. X, Núm. 27, pp. 42-65, DOI: https://doi.org/10.22201/ iisue.20072872e.2019.28.428 [consulta: fecha de última consulta]. 


\section{ANEXO 1. Produções académicas selecionadas por título e país de origem}

\begin{tabular}{|c|c|}
\hline Título das produções acadêmicas & País \\
\hline P1- Sujeitos com deficiência no ensino superior: vozes e significados & B \\
\hline P2- O acesso e a acessibilidade de pessoas com deficiência no ensino superior público no Estado do Rio Grande do Sul & B \\
\hline P3- Ações afirmativas e inclusão sustentável de estudantes com limitações por deficiência no Ensino Superior & B \\
\hline P4-Acesso e permanência na Universidade Federal do Rio Grande do Norte sob o ponto de vista do docente e do estudante com deficiência & B \\
\hline $\begin{array}{l}\text { P5- Políticas públicas para inclusão e permanência de alunos com necessidades educacionais especiais no ensino superior: a experiência da Universidade do Estado do } \\
\text { Pará }\end{array}$ & B \\
\hline P6- Um estudante cego no Curso de Licenciatura em Música da UFRN: questões de acessibilidade curricular e física & B \\
\hline P7- A inclusão de alunos com deficiência visual na Universidade Federal do Ceará: ingresso e permanência na ótica dos alunos, docentes e administradores. & B \\
\hline P8- Ingresso e permanência de alunos com deficiência em universidades públicas brasileiras & B \\
\hline P9- As (im)possibilidades da inclusão na educação superior & B \\
\hline P10- A inclusão de alunos com deficiência em cursos presenciais de graduação da Universidade Federal de Juiz de Fora & B \\
\hline P11- Avaliação da aprendizagem de alunos com deficiência: estudo de caso em uma IEs da rede publica de Fortaleza-Ceará & B \\
\hline P12- Politicas de acesso para discentes com deficiência visual no ensino superior: estudo de caso & B \\
\hline P13- Acessibilidade da pessoa com deficiência física: o caso da UFSE-Cidade universitária professor José Aloisio de Campos & B \\
\hline P14- Inclusão no Ensino Superior: um estudo das representações sociais dos acadêmicos com deficiência visual da UFBE & B \\
\hline P15- Políticas de acesso e permanência de alunos com deficiência em universidades brasileiras e portuguesas & B \\
\hline P16- A inclusão no ensino superior: um estudante surdo no Programa de Pós-graduação em Educação & B \\
\hline P17- Para lembrar que você existe: um estudo de caso sobre as politicas de inclusão para os estudantes com deficiência na Universidade Federal do Espirito Santo. & B \\
\hline P18- O movimento inclusivo na perspetiva dos alunos cegos & B \\
\hline P19- Acessibilidade, barreiras e superação: estudo de caso de experiências de estudantes com deficiência na educação superior & B \\
\hline P20- Acessibilidade no ensino superior: instrumento para avaliação, satisfação dos alunos com deficiência e percepção de coordenadores de cursos & B \\
\hline P21- Acessibilidade física e inclusão no ensino superior: um estudo de caso na UFPA & B \\
\hline P22- Análise das condiç̧̃es de acessibilidade no Ensino Superior: Um estudo com pós-graduandos & B \\
\hline P23- Avaliação da acessibilidade no ensino superior: UTFPR-Câmpus Medianeira & B \\
\hline P24- Integração à universidade na percepção de estudantes com deficiência & B \\
\hline P25- Pessoas com deficiência no ensino superior: percepções dos alunos & B \\
\hline P26- Dinâmicas de significação e trajetórias de desenvolvimento: experiências de estudantes com deficiência autodeclarada na Universidade & $\mathrm{P}$ \\
\hline P27- Alunos com Necessidades Educativas Especiais: Estudo exploratório sobre a inclusão no ensino superior & P \\
\hline P28- Inclusão no Ensino Superior: retratos de estudantes com deficiência & $\mathrm{P}$ \\
\hline P29- Ingresso e permanência de estudantes com NEE no Ensino Superior: Um estudo qualitativo & $\mathrm{P}$ \\
\hline P30- Inclusão de alunos com NEE no Ensino Superior: Um estudo de caso na Universidade Estadual de Montes Claros (Unimontes) & P \\
\hline 31- As Transições dos estudantes com Necessidades Educativas Esp & $\mathrm{P}$ \\
\hline
\end{tabular}

Fonte: Teses da CAPES, RCAAP, Repositórios Científicos das Universidades públicas portuguesas e RENATES. 


\section{ANEXO 2. Metodologia das produções, instrumentos utilizados e participantes}

(Brasil e Portugal)

\begin{tabular}{|c|c|c|c|}
\hline & $\begin{array}{l}\text { Abordagem metodológica/ } \\
\text { Tipo de estudo }\end{array}$ & Instrumentos & Participantes \\
\hline P1 & Qualitativa, exploratória; estudo de caso & Entrevista semi-estruturada & 1 cego; 1 visão reduzida; 2 surdos \\
\hline P2 & Quanti-qualitativa; exploratória & Entrevista semi-estruturada & 14 surdos; 7 def. visual; 1 autista; 1 asperger \\
\hline P3 & Qualitativa; exploratória & Bibliográfica; documental; Entrevista semi-estruturada & 18 def. físico-motora 7 def. auditiva; 4 def. visual \\
\hline P4 & Qualitativa; exploratória; estudo de caso & Entrevista semi-estruturada; Observação livre & 7 def. fisica; 3 def. visual; 2 def. auditiva \\
\hline P5 & Qualitativa; exploratória; estudo de caso & Entrevista semi-estruturada; Questionário & 3 def. visual (baixa visão); 1 surdo \\
\hline P6 & Qualitativa; exploratória; estudo de caso & $\begin{array}{l}\text { Entrevista semi-estruturada; Análise documental; Registos fotográficos; } \\
\text { Observação }\end{array}$ & 1 cego \\
\hline P7 & Qualitativa; exploratória; estudo de caso & Entrevista semi-estruturada; análise documental; observação de aulas; & 3 cegos; 1 baixa visão \\
\hline P8 & Quanti-qualitativa; exploratória & Entrevista semi-estruturada; observação; análise documental; artefactos físicos & $\begin{array}{l}12 \text { cegos; } 3 \text { baixa visão; } 11 \text { def. física; } 3 \text { surdos; } 1 \text { def. } \\
\text { intelectual }\end{array}$ \\
\hline P9 & Qualitativa; exploratória & Entrevista semi-estruturada; análise documental & 6 def. auditiva; 2 cegos; 2 baixa visão; 2 def. motora; \\
\hline P10 & Qualitativa; exploratória; estudo de caso & Entrevista semi-estruturada; questionário & 8 def. física; 6 def. visual; 1 def auditiva \\
\hline P11 & Qualitativa; exploratória; estudo de caso & Entrevista semi-estruturada; questionário & $\begin{array}{l}3 \text { def. auditiva; } 2 \text { def. física; } 1 \text { cego; } 2 \text { baixa visão; } 1 \\
\text { multideficiência }\end{array}$ \\
\hline P12 & Qualitativa; exploratória; estudo de caso & Entrevista semi-estruturada & 1 cego \\
\hline P13 & Quanti-qualitativa; exploratória & Entrevista semi-estruturada & 14 def. física \\
\hline $\mathrm{P}_{14}$ & Qualitativa; exploratória & Entrevista semi-estruturada & 6 deficiência visual \\
\hline P15 & Qualitativa; exploratória & Entrevista semi-estruturada & 14 def. fisica \\
\hline P16 & Qualitativa; exploratória; estudo de caso & Entrevista semi-estruturada & 1 surdo \\
\hline P17 & Qualitativa; exploratória & Entrevista semi-estruturada & 6 def. física; 1 cego; 1 baixa visão; 1 multideficiência \\
\hline P18 & Qualitativa; exploratória; estudo de caso & Entrevista semi-estruturada; & 4 cegos \\
\hline P19 & Qualitativa; exploratória & Entrevista semi-estruturada; análise documental; técnica Shadowing & 2 cegos; 2 def. física; 2 surdos \\
\hline P20 & Qualitativa; exploratória & Entrevista semi-estruturada & 4 baixa visão; 3 cegos; 4 def. física; 1 def. auditiva \\
\hline$P_{21}$ & Qualitativa; exploratória & Entrevista semi-estruturada & 5 def. física \\
\hline P22 & Qualitativa; exploratória & Entrevista semi-estruturada & 5 def física \\
\hline P23 & Quanti-qualitativa; exploratória & Escala de satisfação e atitudes de pessoas com def:; entrevista semi-estruturada & 4 def. físicos \\
\hline P24 & Qualitativa; exploratória & Entrevista semi-estruturada; Questionário de Vivências académicas & 2 def. auditiva; 2 def visual; 1 def. física \\
\hline P25 & Qualitativa; exploratória & Entrevista semi-estruturada & 3 def. visual; 1 def. auditiva; 2 def. física; \\
\hline P26 & Qualitativa, longitudinal & Entrevista semi-estruturada; cartas & $\begin{array}{l}2 \text { Défice de atenção; } 1 \text { def. física; } 3 \text { def. visual; } 1 \\
\text { Asperger; } 1 \text { Dislexia }\end{array}$ \\
\hline P27 & Quanti-qualitativa; exploratória & Entrevista semi-estruturada; Questionário de Vivências académicas & 13 def. física \\
\hline P28 & Qualitativa; Investigação-Ação participativa & $\begin{array}{l}\text { I Entrevista semi-estruturada; instrumento "Os retratos"; Notas de Terreno; } \\
\text { Conversas informais }\end{array}$ & 1 def. visual; 2 def. física; \\
\hline P29 & Qualitativa; exploratória & Pesquisa documental; Entrevista semi-estruturada & $\begin{array}{l}5 \text { def. físico; } 1 \text { baixa visão; } 2 \text { daltonismo; } 1 \text { cego; } 2 \\
\text { dislexia }\end{array}$ \\
\hline P30 & $\begin{array}{l}\text { Quanti-qualitativa; Estudo de caso, } \\
\text { exploratória descritiva }\end{array}$ & Pesquisa documental; Entrevista semi-estruturada & 7 def. física; 2 def. visual \\
\hline P31 & Qualitativa; Estudo de caso & Observação; Entrevista semi-estruturada e análise documental & 4 def. física; 2 Asperger; \\
\hline
\end{tabular}

